\title{
MODERNIDADE E IDENTIDADE EM HÓSPEDE POR UMA NOITE, DE SH. I. AGNON
}

\section{MODERNITY AND IDENTITY IN A GUEST FOR THE NIGHT, BY SCH. Y. AGNON}

\author{
Marian Gabani Gimenez*
}

Resumo: Sh. I. Agnon ocupa um lugar muito particular na ficção hebraica moderna, tendo publicado a maior parte de seus romances em um período em que o pioneirismo e o modelo do hebreu novo eram centrais na literatura hebraica. Em lugar de aderir a essas estéticas ideológicas da época, Agnon analisa profundamente a situação do judeu europeu na Modernidade, em constante tensão entre a identidade religiosa e a étnico-nacional. O narrador de Hóspede por uma noite é um imigrante da Segunda Aliá que, entretanto, não reproduz nem o modelo do pioneiro, nem o do judeu desenraizado da literatura hebraica anterior à década de 1910. Ao contrário, como um profético "Observador da Casa de Israel”, parece apontar as rachaduras nos projetos modernizantes tanto na Europa quanto no futuro Estado de Israel.

Palavras-chave: Sh. I. Agnon. Modernidade. Haskalá. Literatura Hebraica.

Abstract: Sch. Y. Agnon has a very particular place in modern Hebrew fiction, having published most of his novels when Hebrew literature revolved around the models of the new Hebrew and the pioneer. Instead of absorbing the ideological aesthetics of the period, Agnon deeply analyses how the European Jew experiences Modernity - as a constant tension between religious and ethnic-national identities. The protagonist of $A$ guest for the night is a SecondAliyah immigrant that does not fit neither the model of the pioneer nor the "uprooted Jew" from the Hebrew literature prior to the 1910s. On the contrary, he seems to assume the prophetic role of the "beholder to the house of Israel", pointing to fissures on the ongoing modernizing projects, both in Europe and in the future State of Israel.

Keywords: Sch. Y. Agnon. Modernity. Haskalah. Hebrew Literature.

O processo de modernização da Europa no início do século 19, ao transformar por completo as estruturas sociais, políticas e econômica vigentes, foi responsável pelo surgimento de novas formas de judaísmo e pela transformação radical da identidade judaica. No entanto, essa mudança revolucionária tem seu embrião na adesão de judeus aos valores iluministas, ainda no século 18, na figura do judeu alemão Moses Mendelssohn (1729-1786), marcando o

\footnotetext{
* Bacharela em Letras (Hebraico) pela FFLCH-USP. Email: <marian-gabani@ hotmail.com>.
} 
início do período que ficou conhecido como Hascalá, o Século das Luzes judaico. De maneira geral, os judeus adeptos dos valores da Hascalá - os maskilim - defendiam que era possível aos judeus se integrarem à sociedade europeia iluminista sem que perdessem sua identidade judaica. No mundo intelectual, o Iluminismo europeu minava o monopólio do cristianismo, permitindo uma nova visão de judaísmo. Faltava, então, que esse monopólio ruísse também nos âmbitos sociais, políticos e econômicos.

Em 1782, o imperador habsburgo José II foi o primeiro monarca europeu a promulgar um édito de tolerância aos judeus, dando início à modernização das comunidades súditas do Império Austro-Húngaro. O ingresso dos judeus na Modernidade tem como marco histórico sua emancipação alguns anos após a Revolução Francesa. Pela primeira vez aos judeus eram concedidos os mesmos direitos civis que ao resto da sociedade - poderiam se tornar cidadãos franceses de fé mosaica se aceitassem assimilar a cultura francesa e abrir mão da estrutura em que viviam desde o período medieval. A emancipação judaica se espalhou pelos territórios conquistados por Napoleão, e a concessão total de direitos civis na Europa Central ocorreu a partir da metade do século 19.

O processo de emancipação e de modernização marcou profundamente a identidade judaica. A separação entre Igreja e Estado e os valores de Liberdade, Igualdade e Fraternidade minaram a autonomia judaica das kehilot - forma de organização social e econômica judaica que prevaleceu durante a Idade Média europeia - e alçaram os judeus a um novo status. A administração autônoma segundo a halachá, a lei judaica, deu lugar à submissão a uma lei de Estado e laica, separando a religião e o Estado também para os judeus. O judaísmo rabínico perde, assim, sua hegemonia, dando lugar a diferentes visões, a partir tanto de definições identitárias endógenas quando exógenas, do que é ser judeu. Em outras palavras, “o judaísmo moderno separou a) os judeus e o judaísmo, b) os judeus do judaísmo e, c) o judaísmo de uma fonte última de autoridade" (SORJ, 2005, p. 281).

No entanto, a categoria de "cidadão de fé mosaica" inseriria o judaísmo como categoria unicamente religiosa, conferindo ao indivíduo a nacionalidade do Estado do qual é cidadão e obliterando qualquer caráter nacional que o judaísmo possa ter. O mesmo processo que resultou na modernização e emancipação dos judeus parece ter falhado em absorvê-los como cidadãos nacionais, e a separação entre Estado e Igreja, que classificaria o judaísmo como religião, acabou por fortalecer, de certa forma, a identidade judaica enquanto identidade étnico-nacional, resultando, entre tantos outros movimentos, no nacionalismo secular judaico, o Sionismo em suas diversas correntes, em paralelo a outros nacionalismos europeus. No Leste Europeu, onde 
os ventos da Modernidade tardaram a soprar ${ }^{1}$, os judeus sofreram com os movimentos nacionalistas do século 19, que resultaram em pogroms e em outros movimentos discriminatórios, uma vez eram vistos como a "nação dentro da nação", uma espécie de corpo estranho dentro do organismo nacional.

A região da Galícia, atualmente parte da Polônia e da Ucrância, foi o palco de muitas tensões políticas e embates identitários. Por ser uma região fronteiriça entre Europa Central e Oriental, sofreu influência das mais diversas concepções e visões de mundo. Se, por um lado, grande parte de seus territórios eram domínio do Império Austro-Húngaro até a Primeira Guerra Mundial, muitos grupos nacionalistas minoritários reinvindicavam a posse da terra, demonstrando apego aos ideais e à identidade de seus antepassados. Dentro dos grupos judaicos, havia os que aderiram à proposta assimilatória, modernizante e, principalmente, germanizadora da monarquia vienense, ao passo que outros judeus resistiram a esse processo, mantendo-se apegados às tradições religiosas. Vivendo desde a Idade Média nos shtetlech (plural de shtetl, "cidadezinha" em iídiche), pequenas cidades relativamente isoladas de populações judaicas, esse último grupo ficou conhecido como Ostjuden, judeus do leste, e era visto, inclusive pelos judeus germanizados, como atrasados, incultos, portadores de uma tradição arcaica e antimoderna.

O fim da Primeira Guerra levou ao desmantelamento do Império Austro-Húngaro, fortalecendo os movimentos nacionalistas nos países até então súditos de Viena. Se antes os shtetlech já passavam por um processo de desintegração como consequência das políticas assimilatórias, nesse momento esse processo se torna mais acentuado, ameaçando, inclusive, os judeus germanizados, vistos como um corpo estranho no organismo nacional - por um lado, leais à coroa habsburga; por outro, parte de um grupo étnico-nacional distinto. A Modernidade, dessa forma, foi incapaz de integrar o judeu à sociedade geral tanto em sua faceta religiosa quanto em sua faceta étnico-nacional. É nesse universo em desintegração que se desenrola a narrativa do romance Hóspede por uma noite, de Sh. I. Agnon (1887, Buzcazc - 1970, Jerusalém). Escrito em 1938 e publicado em 1939, Hóspede por uma noite se passa em Szibusz, um shtetl fictício na região da Galícia, que muitos críticos identificam como uma representação de Buczacz, cidade natal do autor, após os desastres dos pogroms e da Primeira Guerra Mundial,

\footnotetext{
${ }^{1}$ Na Rússia, por exemplo, a emancipação chegou apenas em 1917, com a Revolução. Apesar da existência de um movimento iluminista judaico russo, sob o domínio czarista os judeus sofriam não apenas com a ausência de direitos, mas também com ataques anti-judaicos altamente violentos, como os pogroms de 1881 e 1882.
} 
quando o Império Austro-Húngaro e a cultura germânica já não dominam a região, que agora sente o crescimento dos movimentos nacionalistas eslavos.

Em um primeiro olhar, parece tratar-se de um enredo simples, uma espécie de diário de viagem do narrador-personagem que, saindo da Terra de Israel, visita sua cidade natal registrando cada um dos "causos" a seu redor e cada um dos tipos sociais do judaísmo galiciano, herdeiros das diferentes vertentes ideológicas e religiosas surgidas no século 19. Veremos, no entanto, que essa jornada revela, mais do que a diversidade cultural e social, a busca do narrador por uma identidade que lhe é negada justamente por conta do caráter ambivalente da Modernidade.

Não é pouco significativo que o narrador chegue a Szibusz às vésperas do Yom Kippur, o Dia do Perdão. Data mais sagrada do calendário judaico, o Yom Kippur é o dia em que se encerram os Yamim Nora 'im, os Dias Temíveis, nos quais cada indivíduo deve refletir a respeito de seus próprios erros, para que possa, no último dia, obter o perdão de Deus e dos homens aos quais fez algum mal. A reza termina com a "reafirmação da fé na unidade e na universalidade de Deus e, ao som do schofar, [a comunidade] reassume as suas eternas responsabilidades dentro da Aliança que Deus concluiu e mantém com Seu povo Israel” (REHFELD, 2003, p. 204). O que o narrador encontra é uma sinagoga - a Grande Sinagoga, centro litúrgico da cidade - que perdera o esplendor de outrora nas noites de Yom Kippur. As rezas, ao contrário do que se espera em um dia tão sagrado, não se alongaram, exceto pelo Kadisch, a reza pelos mortos: "Não houve ninguém que não dissesse a prece pelos mortos" (AGNON, 2014, p. 52). A sinagoga devastada e saqueada torna-se metonímia da condição de Szibusz, cujo nome é um substantivo derivado do verbo hebraico leshabesh ("estragar", "adulterar", "danificar")2, e de seus habitantes, e as referências do narrador a trechos dos livros sagrados (por exemplo, "meus são o ouro e a prata", AGNON, 2014, p. 55, citando Ageu 2:8) diante do estado da Grande Sinagoga e da Casa de Estudos traçam de forma irônica para o leitor os contornos da desintegração do mundo do shtetl. Ainda, o Yom Kippur desse ano não é um momento de teshuvá, de retorno (a qualquer que seja o caminho). Ao contrário, é um momento de abandono no qual os próprios judeus de Szibusz, diante da perplexidade e da falta de esperança, tornam-

\footnotetext{
${ }^{2}$ Cabe ressaltar que a forma lexical utilizada é a de shem hapeulá, isto é, não se trata de uma cidade "estragada" (meshubeshet, forma utilizada como adjetivo), mas de algo que é o próprio processo de danificação. O processo não está, portanto, concluído e de forma alguma é estático e irreversível como uma adjetivação.
} 
se os bodes expiatórios lançados ao deserto no Dia do Perdão: “Agradável ou não, seja lá como for, abandonamos a cidade logo depois da festividade" (AGNON, 2014, p. 59).

É nesse momento da narrativa também que, pela primeira vez no romance, uma das grandes questões do judaísmo será posta na mesa: se Deus está com o povo de Israel, como esses tragédias - os pogroms, principalmente - sobrevieram aos filhos de Israel? A personagem Elimelekh Imperador, cujo nome carrega forte ironia com a combinação de "meus deus é rei" e "imperador", marca o embate entre os judeus que se apegaram à cultura germânica de Viena e ao hedonismo burguês e os que continuaram a viver nos schtetlech, ao mesmo tempo em que vê a inconsistência da visão de mundo religiosa:

Esses turistas mora em belas metrópoles e passeiam pelo mundo e a nós ordenam que fiquemos em nosso lugares, onde rezaram nossos antepassados, a fim de que tenhamos o privilégio de morrer pelo martírio da fé e de sermos louvados pelas nações do mundo, mostrando-lhes quão belo é o povo de Israel, que aceita os seus sofrimentos e morre por Ele. (AGNON, 2014, p. 61).

Dessa forma, os primeiros capítulos do romance ambientam o leitor no universo de rupturas e contradições do judaísmo pós-guerra no Leste Europeu. E nem tradição, nem modernidade se sustentam nesse mundo em convulsão.

A partir desse panorama inicial desenrola-se uma trama central - a estadia de quase um ano do narrador e sua tentativa de reviver a casa de estudos, cuja chave lhe fora confiada pelos que abandonariam a cidade - que se encontra com diversas outras tramas secundárias, em uma sucessão de pequenos acontecimentos nas mais diversas esferas sociais que se entremeiam, formando uma imagem ao mesmo tempo dinâmica e desoladora de Szibusz. O que há de comum a todas essas tramas é que elas estão, de certa forma, centralizadas no narrador - sendo o narrador mesmo um escritor, tudo está posto a partir de seu olhar que, embora pareça imparcial, revela-se muito seletivo (por exemplo, as diversas vezes em que diz que determinada personagem "contou o que contou", seguido pela seleção dos momentos que parecem, aos olhos do narrador, relevantes ao leitor ou a sua própria narrativa). Ainda, o fato de ser um visitante oriundo da Terra de Israel cerca-o com uma aura quase mítica, que leva os habitantes de Szibusz, mesmo os que não se opõem ao narrador ideologicamente e o culpabilizam por seus fracassos pessoais, como Ierukham Liberto, a tê-lo em alta conta: "Um judeu da Terra de Israel veio nos visitar" (AGNON, 2014, p. 225); "vocês devem saber que sou um judeu da Terra de Israel (...)" (AGNON, 2014, p. 276); "Você, meu pintainho, esteve lá em Jerusalém, ou seja, na Terra de Israel, e lá se sabe de tudo, diga-me, meu pintainho, quando virá o Messias?”(AGNON, 2014, 
p. 333); "Uma mulher apontou-me com o dedo, mencionando o nome da Terra de Israel" (AGNON, 2014, p. 348); entre outras passagens.

A aura mítica que cerca o narrador ganha força irônica se levarmos em consideração o momento histórico em que Hóspede por uma noite é escrito e publicado. Entre 1890 e 1910, conviviam no mainstream da literatura produzida em hebraico e, em grande parte, na Europa dois modelos literários: a) o judeu da diáspora tal como cristalizado pela literatura da Hascalá; e b) o judeu diaspórico desenraizado, um modelo de vanguarda baseado no anterior e permeado pela visão sionista negativa a respeito da Diáspora. Entre 1910 e 1930, quando a Palestina tornase o centro da Literatura Hebraica, o modelo do hebreu novo torna-se o modelo central da vanguarda em detrimento dos modelos antigos. O hebreu novo está em perfeita consonância com a imagem idealizada do pioneiro criada na Segunda Aliá: “é um judeu jovem, pioneiro (...), amante do trabalho, ligado à natureza, apaixonado pelo país." (ROZENCHAN, 2004, p. 13). Como escritor, Agnon pôde observar diante de si todos esses modelos de vanguarda sendo suplantados por novos modelos - nas décadas de 30 e 40, o israelense nativo, o "sabra", será o modelo da vez, como uma evolução do anterior.

Como o narrador, o autor também foi um imigrante da Segunda Aliá (segunda onda migratória) e, como tal, vivenciou todas as criações ideológicas desse movimento, que, iniciado em 1904, um ano após o pogrom de Kishinev, foi marcadamente distinto da primeira onda migratória (1881 - 1903) por diversos motivos, dentro dos quais se destaca o ativismo político dos imigrantes nos assuntos públicos. Contrários ao processo de normalização que acometeu os imigrantes da Primeira Aliá, os judeus da Segunda Aliá, vindos, em sua maioria, do Império Russo, onde os ideais socialistas ganhavam cada vez mais força, viam-se a si mesmos como pioneiros livres de qualquer interesse individual, visando apenas o futuro da comunidade judaica como um grupo essencialmente nacional em Terras de Israel. Embora o número de imigrantes da Segunda Aliá fosse pequeno (menos de dez mil judeus), a estrutura social e política para o Ischuv tal como moldada nesse período foi o modelo para as décadas seguintes, inclusive nos primeiros anos do Estado de Israel, no qual a elite política era formada, em números proporcionais, em grande parte por imigrantes de segunda onda. Por outro lado, tanto o narrador quanto Agnon tiveram em suas cidades natal sólida formação religiosa e tradicional, que entram em profunda contradição com os valores secularistas do Sionismo no qual se baseavam as ondas migratórias.

O narrador, embora portador de uma aura especial, não é em nada semelhante à imagem do pioneiro idealizado, afastando-se de parte das construções ideológicas da Segunda Aliá. Sua identidade, portanto, é construída na recusa a esse modelo. Isso não implica, no entanto, na 
rejeição ao Sionismo como única solução viável à "questão judaica". A visão do narrador a respeito da Terra de Israel vai além da visão religiosa e messiânica tradicional do judaísmo, e este se mostra simpático, inclusive, ao processo de colonização da terra, sem, no entanto, identificar-se com esse processo. As críticas do narrador ao movimento sionista são direcionadas às atividades sionistas na Diáspora, como se nota pelo tom irônico que este usa quando se refere a Gordonia (AGNON, 2014, p. 153), um grupo de sionistas em Szibusz seguidores de Gordon, "primeiro pensador judeu importante cujas ideias surgiram do confronto com a própria realidade da Palestina" (AVINERI, 1983, p. 173) e que defendia, mais do que a teoria, a prática, levantando a bandeira do trabalhismo e do vínculo do homem com a natureza - a natureza da Terra de Israel.

Na construção da identidade do narrador, recusa-se também o secularismo, evidenciado por sua preocupação, mais do que qualquer outra personagem - inclusive o rabino -, em reviver a Casa de Estudos e pela visão messiânica do arrebatamento dos lugares sagrados, inclusive da própria Casa de Estudos, como indica a preocupação em guardar a chave consigo, mesmo tendo voltado à Terra de Israel. Nesse apego à tradição, que, nesse caso, articula-se à adesão a um movimento nacionalista eminentemente moderno como o Sionismo, o narrador não se vê totalmente como tradicional - embora seja o último dos guardiões da tradição em uma cidade que já não consegue reconhecer em meio às ruínas -, nem como um pioneiro - embora defenda o trabalho dos pioneiros na Palestina, ou na Terra de Israel, cuja Torá, segundo o próprio narrador, é pura e superior. Não pode, assim, conformar-se a esse mundo de binarismos: "quando eu era jovem frequentador da casa de estudos, esta fugia de mim, e quando cheguei à Terra de Israel, a Terra fugiu de mim” (AGNON, 2014, p. 124).

Se aceitamos a leitura do sociólogo Zygmunt Bauman (apud Waldman, 2004), segundo a qual a Modernidade está estruturada no binarismo e que qualquer elemento que não se possa categorizar de um lado ou do outro deve ser eliminada ou, na melhor da hipóteses, vista com desconfiança, o narrador de Hóspede por uma noite está preso nesse limbo do mundo moderno, mundo este responsável por cindir a identidade judaica em identidade religiosa ou identidade étnico-nacional. Ao se revelar escritor (em hebraico "sofer"), o narrador se alça ao status dos homens que escrevem o sagrado rolo da Torá, realçando o caráter profético - no sentido bíblico, aquele que aponta as imoralidades e os desvios de conduta do povo de Israel - do "observador da Casa de Israel”, expressão do profeta Ezequiel utilizada pela crítica para se referir ao papel dos escritores de língua hebraica até a década de 1970. Como alguém que antevê a História, Agnon diagnostica que o binarismo moderno será incapaz de integrar o judeu em todas as suas facetas, tanto na Europa moderna quanto no eminentemente moderno Estado de Israel que será 
criado em breve. Nesse meio tempo, sua personagem permanece como um hóspede estrangeiro em sua própria terra.

Referências bibliográficas

AGNON, Sch. I. Hóspede por uma noite. São Paulo: Perspectiva, 2014.

AVINERI, Shlomo. La idea sionista: notas sobre el pensamiento nacional judío. Jerusalém: La Semana Editora, 1983.

EISENSTADT, S. N. "Os principais estágios no desenvolvimento institucional do Ischuv. Características específicas das principais aliot” in Sociedade Israelense. São Paulo: Perspectiva, 1977. pp. 45-69.

KRAUSZ, Luis S. "Assimilação e melancolia" in Ruínas recompostas - Judaísmo centroeuropeu em Aharon Appelfeld, Joseph Roth e Georg Hermann. São Paulo: Humanitas, 2013.

REHFELD, Walter I. Nas sendas do Judaísmo. São Paulo: Perspectiva, 2003.

ROZENCHAN, Nancy. "Traços de personagens bíblicos na construção de personagens discriminados na literatura hebraica contemporânea", Cadernos de Língua e Literatura Hebraica, São Paulo, n. 9, 2011, p. 13-31.

SORJ, Bernardo. "Identidade e identidades judaicas" in AMÂNCIO, Moacir (org.). Ato de presença: hineni. São Paulo: Humanitas, 2005. pp. 227-285.

WALDMAN, Berta. "Figuras fora de foco: a judia e o soldado alemão" in Linhas de força: Escritos sobre literatura hebraica. São Paulo: Humanitas, 2004. 